\title{
Measurements and correction of the 1/1 error field in Wendelstein $7-\mathrm{X}$
}

\author{
S.A. Bozhenkov ${ }^{1}$, M. Otte ${ }^{1}$, C. Biedermann ${ }^{1}$, M. Jakubowski ${ }^{1}$, \\ S.A. Lazerson ${ }^{2}$, T. Sunn Pedersen ${ }^{1}$, R.C. Wolf ${ }^{1}$ and W7-X team \\ ${ }^{1}$ Max-Planck-Institut für Plasmaphysik, D-17491 Greifswald, Germany \\ 2 Princeton Plasma Physics Laboratory, Princeton, New Jersey 08543, USA \\ E-mail: sergey.bozhenkov@ipp.mpg.de
}

\begin{abstract}
In this paper, vacuum flux surface mapping is used to measure the $1 / 1$ error field in Wendelstein 7-X. Two methods for discriminating the $1 / 1$ perturbation from other co-resonant modes are applied: measurements of the helical axis shift in a magnetic configuration with the rotational transform barely above one on the axis; and measurements of the edge island structure with cancellation of intrinsic $5 / 5$ islands by divertor control coils. The normalized radial $1 / 1$ amplitude in Boozer coordinates is found to be about $0.8 \cdot 10^{-4}$ in the first case and about $0.5 \cdot 10^{-4}$ in the second one, with the discrepancy being attributable to different currents in the planar coils. The $1 / 1$ error field can be reliably compensated by using error field trim coils with currents about $100 \mathrm{~A}$. This compensation also helps to identify the $2 / 2$ error field of about $0.6 \cdot 10^{-4}$. During plasma operation in divertor configurations, it is confirmed that the present $1 / 1$ field leads to asymmetries in the power distribution and that the $1 / 1$ compensation improves this symmetry.
\end{abstract}




\section{Introduction}

Wendelstein 7-X [1,2] is an optimized stellarator that aims to demonstrate relevance of stellarators as a fusion reactor [3]. To that end, verification of divertor performance for heat and particle exhaust and the subsequent realization of the steady state operation [3, 4] are among the main priorities of the project. In W7-X, a multi-Xpoint divertor configuration, an island divertor [5, 6], is achieved by using intrinsic magnetic islands at the plasma edge [7]. Discrete target plates intersect the magnetic islands; and, thus, the area of plasma wall interaction is topologically separated from the core confinement region. Such a configuration is predicted to provide sufficient power spreading and has potential for stable power detachment and impurity retention in the islands [8, 9]. In addition, divertor properties can be easily controlled in experiment by suitable normal conducting coils, since only a relatively small radial field $b_{r}$ of the order of $10^{-4}-10^{-3}$ is required to influence the islands. The main coil system of W7-X is superconducting as required for the steady state operation.

Divertor islands are formed at the resonant position, where the rotational transform $t$ is equal to the ratio of toroidal $n$ and poloidal $m$ mode numbers $n / m$ of the island chain. Planar coils of W7-X allow one to vary the edge $t$ between 0.83 ("low-iota") and 1.25 ("high-iota"). In this range, divertor configurations $m / n=6 / 5,5 / 5$ and $4 / 5$, with 6,5 and 4 islands in the poloidal cross-section respectively, are possible [10]. Configurations with $5 / 5$ islands are usually favoured because of the distance between the island chain and baffles, the pumping gap position [8], and also because of the suitable island control coils [4,6]. It is worth noting that the magnetic configuration can be significantly varied even for the fixed rotational transform at the boundary by changing currents in 5 types of non-planar coils, e.g. in order to affect bootstrap current, neoclassical transport and MHD stability [11. For example, the "high-mirror" configuration minimizes the bootstrap current and, consequently, avoids changes of the strike line due to the plasma pressure.

Island divertor configurations are sensitive to small resonant error fields of the order of $10^{-4}$, as they modify the edge topology by superimposing additional undesired islands. Specifically, the 5/5 divertor configurations of W7-X are strongly influenced by $1 / 1,2 / 2$, etc. error fields. In an ideal case, the outflowing power is evenly distributed between all ten divertor modules, five at the bottom and five at the top of the device according to the stellarator symmetry. Error fields modify this power distribution and result in locally excessive heat flux densities, higher power fractions delivered to some divetor units, and unintended potential heat loads to other in-vessel components.

Figure 1 presents results of field line diffusion simulations [12] with a deliberately superimposed $1 / 1$ perturbation for the standard W7-X divertor configuration with $5 / 5$ islands at the edge for relevant diffusion settings. The standard configuration is realized experimentally by supplying equal currents to all types of the non-planar coils and no currents to the planar coils. The $1 / 1$ amplitude is defined in this paper as amplitude of the normal component of the perturbation field, normalized by the average field on the 


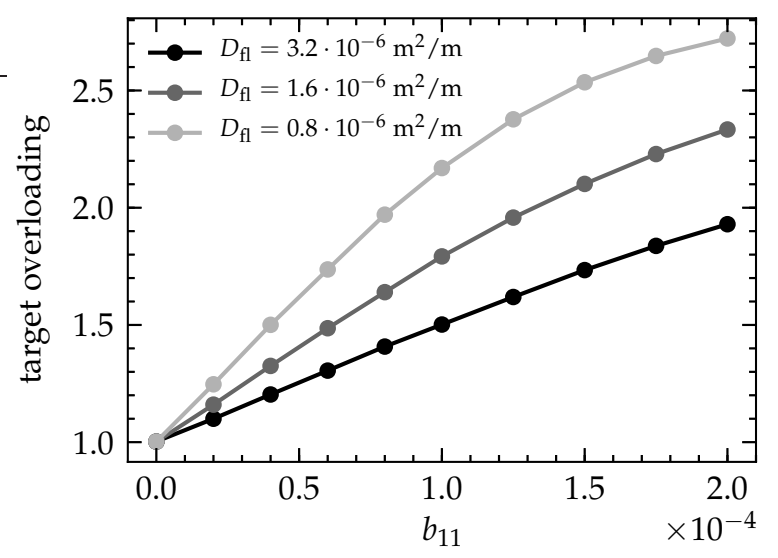

Figure 1: Overloading of divertor targets by 1/1 error field. Results of field line diffusion simulations are shown for different values of the field line diffusion coefficient defined as $D_{\mathrm{fl}}=D_{\perp} / v_{\|}$, where $D_{\perp}$ is the perpendicular diffusion coefficient and $v_{\|}$is the parallel streaming velocity.

magnetic axis. A precise definition is given later in the paper. The power fraction to the most loaded module is shown in figure 1 as the ratio between the actual value and the ideal value of one tenth. The target overloading increases with the amplitude of the perturbation, but also depends on the assumed diffusion, with higher diffusion helping to spread the power more evenly.

A considerable deviation from the symmetry in the experiment would require extra cooling capabilities and might limit the heating power allowed for the steady state operation. Besides, it can complicate interpretation of experimental results. For these reasons, error fields should be minimized and unavoidable errors have to be compensated.

Error fields arise due to manufacturing and installation imperfections of the coils, presence of current buses and ferromagnetic materials close to the plasma, and asymmetric electromagnetic deformations of the coil system. The need to minimize error fields was realized early in the construction phase of W7-X. Accordingly, the accuracy of coil manufacturing and of every assembly step was monitored with metrology [13]. Errors accumulated for non-planar coils were compensated by the final adjustment of module positions [14,15], which helped to reduce the normalized 1/1 component below $0.2 \cdot 10^{-4}$. Nonetheless, the subsequent assembly steps that followed the module positioning, including the interconnection of modules and the removal of temporary supports, are able to cause a $1 / 1$ perturbation of about $1 \cdot 10^{-4}$ as predicted by finite element calculations [15]. An experimental verification and compensation of error fields, in particular of the $1 / 1$ mode, is, therefore, necessary. For compensation of error fields, W7-X is equipped with ten divertor control coils and five error field trim coils [16], each of these coils can be powered individually.

The W7-X operation started with a limiter campaign OP1.1 [17-19], in which five poloidal graphite limiters were used instead of the island divertor to define the plasma 


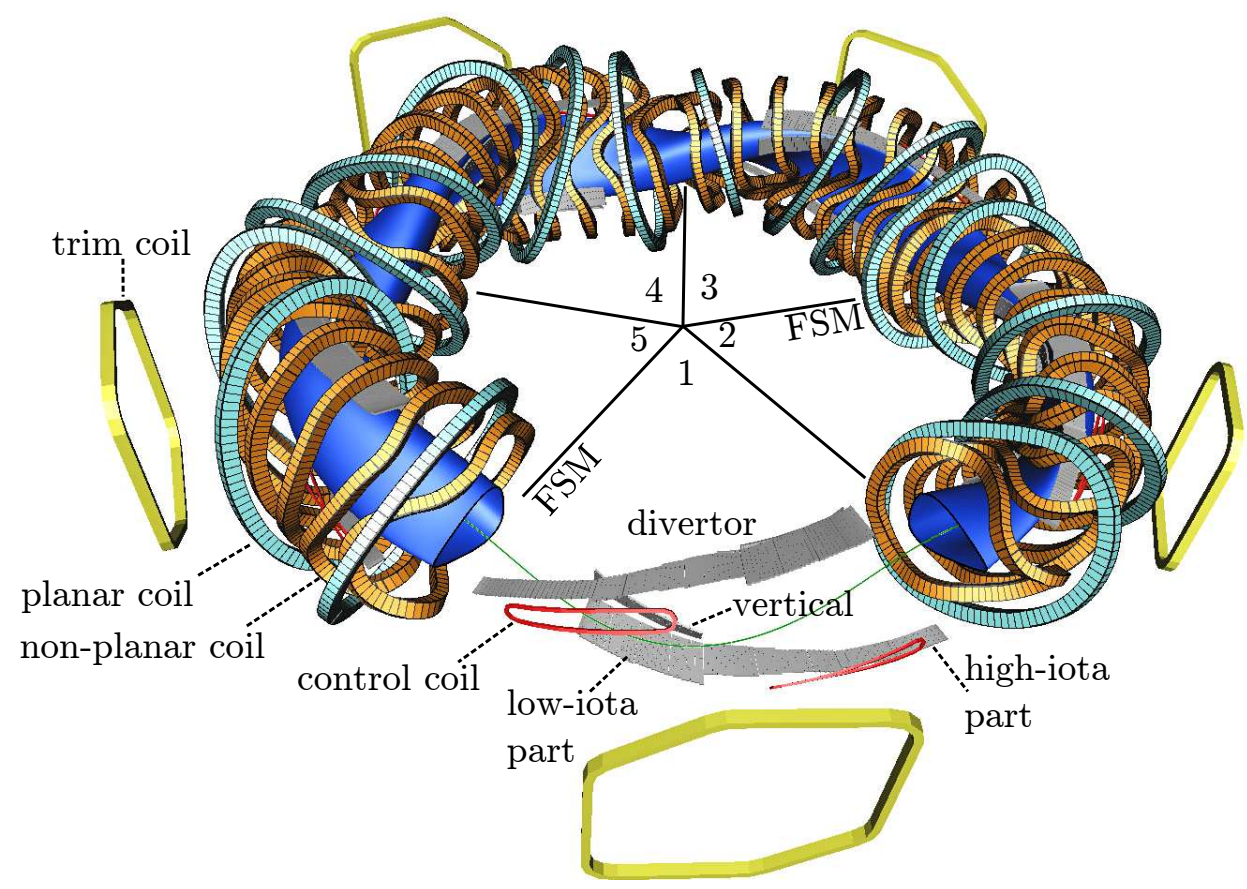

Figure 2: Main components of the W7-X experiment. The following coil systems are shown: non-planar coils (orange), planar coils (light blue), trim coils (yellow) and divertor control coils (red). The non-planar and planar coils, and also the flux surface are not shown in module 1 to detail the divertor structure. The divertor includes a vertical and a horizontal target. The horizontal target consists of the low-iota and highiota parts. The flux surface mapping diagnostic (FSM) is located between modules 5 and 1 and between modules 2 and 3 .

edge at the rotational transform of about 0.87 [20]. The quality of vacuum flux surfaces was verified before the first plasma experiments with the aid of flux surface mapping. In these mapping measurements, the overall required precision of the W7-X construction was successfully confirmed [21] and an about $2 \%$ reduction in the rotational transform caused by coil deformations was found at the field of $2.5 \mathrm{~T}$ [22]. From the error field spectrum only the $m / n=2 / 1$ component was assessed, and its amplitude was found to be below $0.1 \cdot 10^{-4}[23]$. Error field components relevant for the divertor operation were not addressed, because of a minor effect on the limiter operation and due to restrictions for the operation of the magnet system at that time. A non-resonant modification of the heat flux to the limiters was studied in plasma experiments with a strong $1 / 1$ field intentionally superimposed with trim coils [24,25].

Divertor experiments at W7-X started in the second half of 2017 [3, 26]. They were preceded by new flux surface measurements with more attention to the $1 / 1$ error field. Results of these experiments are summarized in the present paper. The $1 / 1$ error field is visualized with two approaches: (i) from the axis shift in the high-iota configuration, where the rotational transform is only just above one; and (ii) from detailed studies of the edge island structure with cancellation of the intrinsic $5 / 5$ islands. The $1 / 1$ 


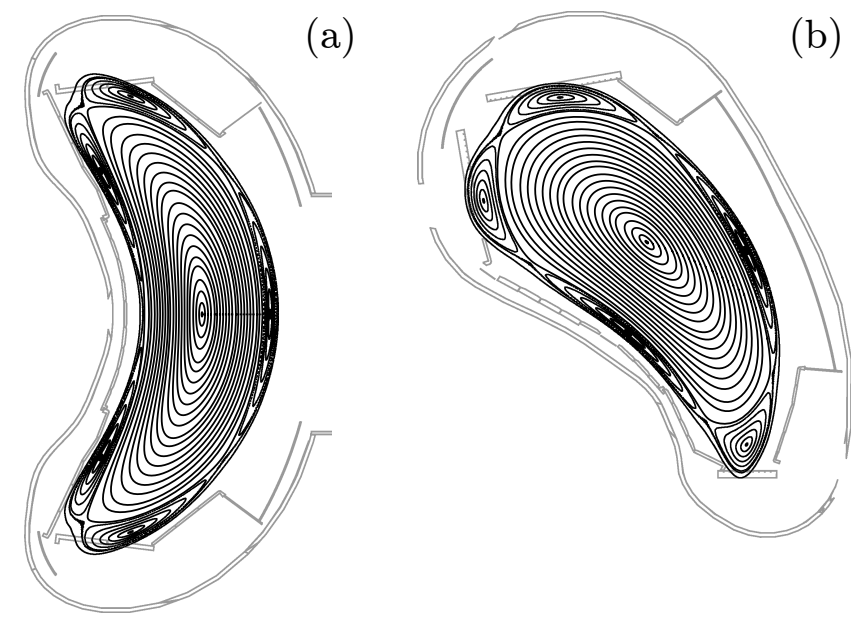

(b)

(c)

Figure 3: Typical cross-sections of W7-X. Poincaré plots and the wall components are shown in thee cross-sections of one half module. (a) - bean-shaped cross-section, $\varphi=0^{\circ}$; (b) - droplet-shaped cross-section, $\varphi=18^{\circ}$; (c) - triangular-shaped cross-section $\varphi=36^{\circ}$.

amplitude changes between the two configurations from about $0.8 \cdot 10^{-4}$ in the first case to about $0.5 \cdot 10^{-4}$ in the second one, although the error bars are rather large in both cases. The $1 / 1$ error field can be readily compensated with the trim coils, which also helps to identify the $2 / 2$ perturbation of about $0.6 \cdot 10^{-4}$. These findings from the flux surface mapping are also supported by observations of the power distribution between divertor units during the plasma operation. The $1 / 1$ compensation noticeably improves the symmetry of the power distribution.

\section{Experimental method}

Wendelstein 7-X is a fivefold symmetric stellarator. It consists of five identical modules repeated toroidally, as shown in figure 2. Flux surfaces are created by the superconducting non-planar and planar coil systems. The non-planar coils are optimized modular coils that generate both toroidal and poloidal field components. The planar coils can be used to change the horizontal position and to adjust the rotational transform by changing the toroidal field. There are five different types of the non-planar coils and two types of the planar coils. Thus, a W7-X magnetic configuration can be described by specifying seven currents. To compensate error fields, five trim coils are installed around the machine. In addition, divertor control coils, two coils per module, are available for the fine adjustment of divertor islands.

The W7-X divertor consists of ten identical divertor units installed at the top and at the bottom of each stellarator module according to the symmetry, as presented in figure 2. The strike lines can be located on the vertical target, on the low-iota part of the horizontal target or on the high-iota part of the horizontal target. The detailed power distribution between these zones depends on the magnetic configuration. 
The shape of W7-X flux surfaces changes with the toroidal angle. Poincaré plots for three typical cross-sections are given in figure 3 for the standard configuration with $5 / 5$ islands at the edge. The plasma shape changes from the bean shape at $\varphi=0^{\circ}$, to the droplet shape at $\varphi=18^{\circ}$ and to the triangular shape at $\varphi=36^{\circ}$. For the second half of a module, i.e. between $-36^{\circ}$ and $0^{\circ}$, the shape of flux surfaces is the same but inverted upside down. The shape of flux surfaces is repeated in each module, if there are no error fields breaking the fivefold symmetry. It can be seen in figure 3 that also the divertor interaction changes with the toroidal angle. In particular, there is no contact between the edge islands and the first wall in the triangular plane.

Stellarator flux surfaces are completely formed by external coils with no plasma currents required. For this reason, they can be conveniently visualized without plasma by mapping them with an electron beam, which is a well established experimental technique [27,28]. In this method, a low energy electron beam is launched along field lines and the position of the beam is detected after multiple toroidal transits to create a flux surface cut. It is this method that is applied here too.

In W7-X, $\mathrm{LaB}_{6}$ electron emitters of about $2 \mathrm{~mm}$ in diameter with a typical acceleration voltage below or equal to $50 \mathrm{~V}$ are mounted on three movable rods. Two such rods are installed from the opposite top and bottom ports in a triangular cross-section between modules 5 and 1 and one from the top port between modules 2 and 3. All three rods can be moved radially as well as swept poloidally, giving access to almost the full poloidal cross-section. The rods themselves are aluminium tubes of $10 \mathrm{~mm}$ in diameter and used to detect the electron beam at the same time, for which they are covered with fluorescent $\mathrm{ZnO}: \mathrm{Zn}$ powder. During a single measurement, one of the manipulators, between modules 5 and 1 in this work, is fixed at a position inside the vacuum chamber and is used as an emitter. At the same time, the manipulator between modules 2 and 3 is gradually swept across to visualize the beam after multiple transits. The fluorescence image is observed with a tangential high-sensitivity CCD camera PCO PixelFly QE with an integration time of $60 \mathrm{~s}$ sufficient to record the full detector sweep. Such a measurement provides a cross-cut of a single flux surface. A full set of flux surfaces can be obtained by changing the emitter position and combining the images. Further details of the W7-X flux surface diagnostic can be found in [22].

Flux surface measurements produce a Poincaré cut of flux surfaces in the plane defined by the detector and can be directly compared with field line tracing simulations. Here this comparison is performed with no extra degrees of freedom. The motion of W7-X manipulators including the sweeping was calibrated by using the metrology technique before experiments. This allows one to translate experimental settings for the emitter position to start points for the field line tracing and to calculate a Poincaré plot in the plane defined by the detector sweep. Calculated $3 \mathrm{~d}$ intersection points are then projected using a camera model for a direct comparison with measurements, where the camera model is calibrated to about 50 reference points at the first wall wihin a few pixels. Field line tracing is performed with the standard W7-X web-service [12].

The described simulation procedure usually demonstrates a good accuracy, as can be 

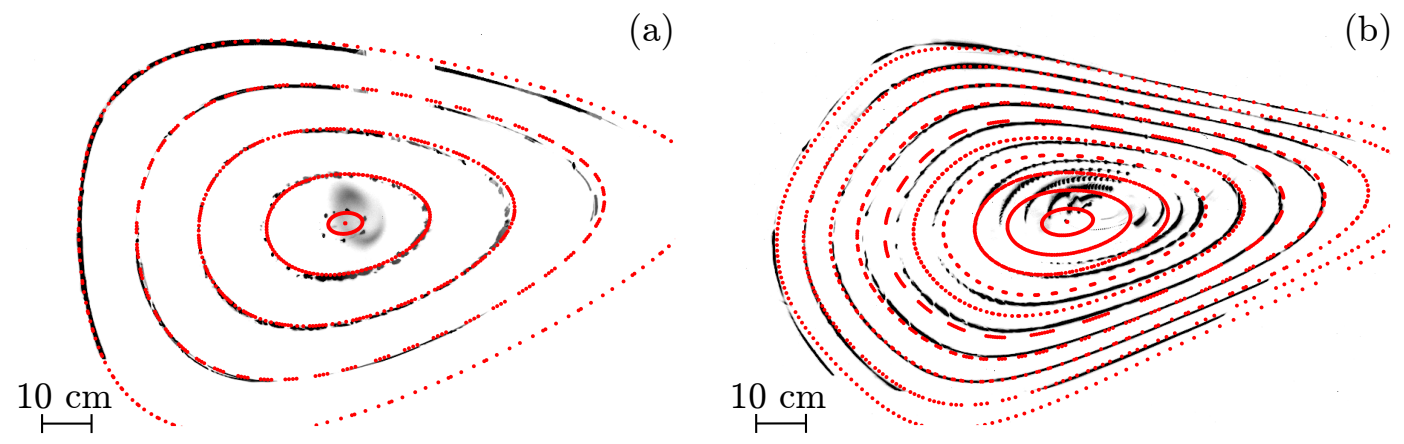

Figure 4: Comparison of measured and simulated flux surfaces for the standard (a) and high-iota (b) configurations. Experimental data are shown in black, simulations for ideal coil geometries are shown in red.

concluded from a comparison with measurements in cases without pronounced error field effects. For example, in the standard divertor configuration, equal currents in the nonplanar coils and no currents in the planar coils, the simulations are in good agreement with measurements for central flux surfaces, as shown in figure 4 a. The small difference for the most central flux surface is mainly due to the uncertainty in the emitter position. It is possible to obtain an even better match for the central surface by a fine adjustment of the start position for tracing, but this path is not followed here. In contrast, the deviation for the outer flux surfaces in figure $4 \mathrm{a}$ is rather caused by a modification of the $5 / 5$ island chain by the $1 / 1$ error field. The island chain itself is shadowed by the divertor and is, therefore, not visible. From this comparison we estimate the accuracy of the method to be about 5 pixels or equivalently about $8 \mathrm{~mm}$, which is also a typical size of the fluorescent spot. It is important to note that no systematic shift is observed in the central part of the standard configuration, i.e. the ideal magnetic axis position is consistent with the measurements.

It can be seen from figure 4 a that not all flux surfaces are imaged completely and with the same density of intersection points. This restriction has two reasons. Firstly, in the vicinity of rational flux surfaces, the electron emitter induces self-shadowing, when the electron beam returns to the emitter position after a finite number of toroidal transits. Secondly, for outer flux surfaces, the poloidal coverage both of the detector and of the camera is limited. In practise, these effects hinder the measurements only in extreme cases.

Error fields can be identified in flux surface measurements from islands they develop at the resonant position. A radial perturbation field of amplitude $b_{m n}$ opens up an island of the following full width in minor radius [29]:

$$
w_{m n}=4 \cdot \sqrt{\frac{R_{0} b_{m n}}{m d t / d r}},
$$

where $R_{0}$ is the major radius and $d t / d r$ is the magnetic shear. The difficulty in measuring the $1 / 1$ error field in W7-X with this approach is to separate it from other co-resonant error fields and from the prevailing intrinsic $5 / 5$ field, as discussed in detail in [30]. This 
can be achieved either by shifting the resonant position towards the axis due to the radial mode decay $\sim r^{m-1}$, or by a sequential compensation of known fields. Alternatively, the $1 / 1$ error field can be determined from the shift of flux surfaces, or the axis shift, in a configuration where the rotational transform is everywhere above one, but the difference $t-1$ is sufficiently small [30]. The shift in minor radius can be estimated in a linear approximation as:

$$
|\delta r|=\frac{R_{0}\left|b_{m n}\right|}{m t+n},
$$

This method isolates the $1 / 1$ field from the other modes because of the aforementioned radial decay. The estimation of the axis shift in equation 2 does not depend on the shape of flux surfaces. The linear approximation assumes a small deviation from the original flux surface. For large deviations changes in the rotational transform and in the mode amplitude have to be taken into account, which is most easily done numerically. In this paper, both the axis shift and the island measurements with cancellation of the $5 / 5$ component by external coils are applied. The axis shift can be measured in configurations close to the high-iota configuration, which are obtained by reducing the toroidal field with the help of planar coils. The island measurements can be performed in any configuration with 5/5 islands at the edge, including standard, high-mirror and narrow-mirror configurations. Here, results for the narrow-mirror configuration are presented, because it was of interest for transport studies during the first half of the experimental campaign. The difference in error fields between the latter three configurations is expected to be small.

Normalized dimensionless error field amplitudes are used throughout this paper. The following definition of radial modes can be derived from the Fourier decomposition of perturbed field line equations in a magnetic coordinate system:

$$
b_{m n}=\frac{1}{r R_{0} B_{0}} \cdot\left(\vec{B} \cdot\left[\frac{\partial \vec{r}}{\partial \theta} \times \frac{\partial \vec{r}}{\partial \varphi}\right]\right)_{m n},
$$

where $r$ is the minor radius related to the enclosed toroidal flux by $\Psi=B_{0} \pi r^{2}, B_{0}$ is the average field on the axis, $\theta$ and $\varphi$ are poloidal and toroidal angles and ()$_{m n}$ is the Fourier mode with the poloidal mode number $m$ and the toroidal mode number $n$. Boozer coordinates are chosen for the representation. A detailed discussion of this definition can be found in [30]. The Fourier decomposition is performed in terms of $m \theta+n \varphi$, and, hence, the resonant modes are actually $-1 / 1,-2 / 2$ etc. However, to stay consistent with the literature and for the sake of simplicity the notation $1 / 1,2 / 2$ is used in this paper.

\section{Experimental results}

\subsection{Measurements of the axis shift}

Error fields can be measured from non-resonant deformations of flux surfaces they impose. Such deformations do not cause changes in the topology, i.e. magnetic islands 
(a)

(b)
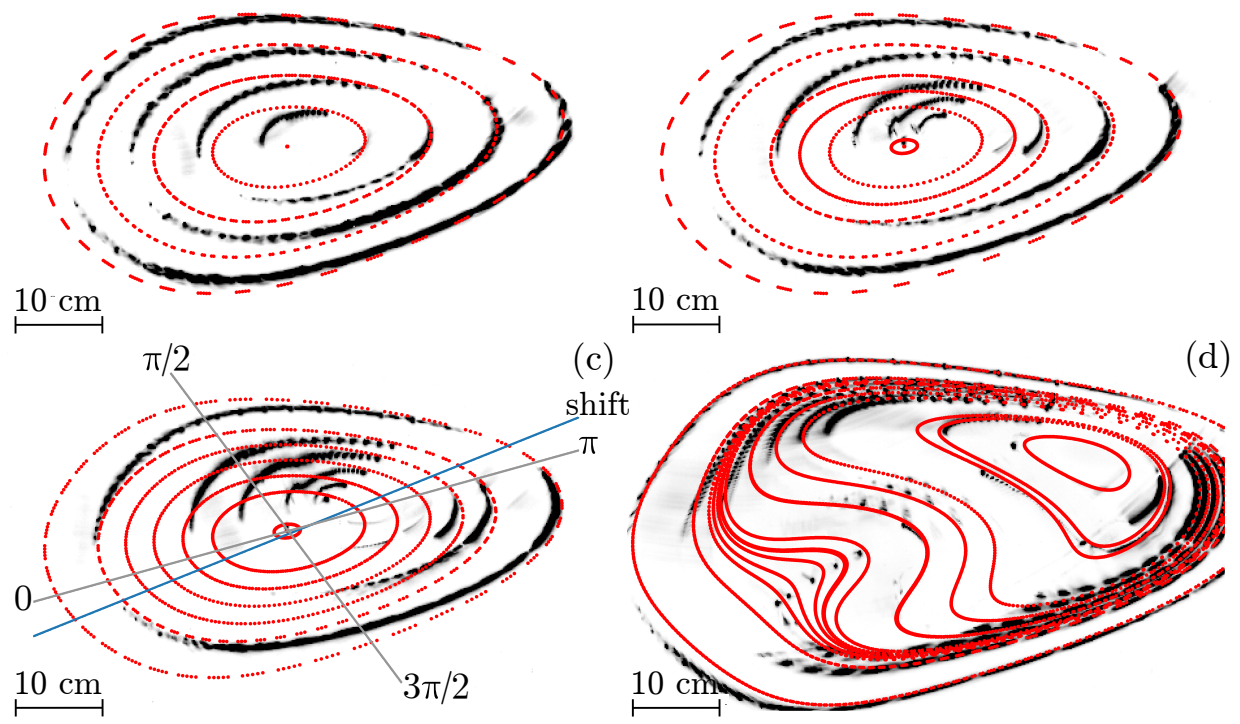

Figure 5: Change of the axis shift with the rotational transform. Measured flux surfaces are shown in black, simulations are shown in red. Simulations are performed with ideal coils for the cases (a)-(c) and with a superimposed 1/1 perturbation for the case (d). In all cases the current in the non-planar coils is $14.2 \mathrm{kA}$. (a) - planar coil current of $-10.2 \mathrm{kA}, t_{0} \approx 1.02$; (b) - planar coil current of $-9.8 \mathrm{kA}, t_{0} \approx 1.01 ;(\mathrm{c})$ - planar coil current of $-9.6 \mathrm{kA}, t_{0} \approx 1.007$; $(\mathrm{d})$ - planar coil current of $-9.0 \mathrm{kA}, t_{0} \sim 1$, for this case the field line tracing includes the $1 / 1$ error field with the relative amplitude of $0.8 \cdot 10^{-4}$.

are not formed. The $1 / 1$ error field results primarily in a helical shift of flux surfaces, with the magnitude of the shift being proportional to the mode amplitude and the direction depending on the mode phase. For measurements of the $1 / 1$ mode from such a shift, the high-iota configuration is the most suitable one in W7-X, because the effect is amplified by the close proximity of the rotational transform at the axis to 1 . In the high-iota configuration, the rotational transform grows from about 1.01 on the axis to 1.25 at the edge, crossing the value of 1.1 at $r / a$ of about 0.75 . For comparison, in the standard configuration the rotational transform changes from about 0.86 on the axis to 1 at the edge, staying below 0.9 for $r / a$ smaller than about 0.75 , so that no measurable axis shift is expected in this case. A comparison of $t$-profiles for these two configurations can be found in [30]. The high-iota configuration is realized by introducing a current in the planar coils with the polarity opposite to that in the non-planar coils, while keeping currents in all non-planar coils equal. The required planar coil current (36 turns) is about $-9.8 \mathrm{kA}$ for the field of $2.5 \mathrm{~T}$, whereas the current in non-planar coils (108 turns) is about $14.2 \mathrm{kA}$.

The 1/1 induced shift of flux surfaces in the high-iota configuration becomes evident if measurements are compared to the corresponding ideal flux surfaces, as presented in figure 4b. The outer flux surfaces, where the difference $t-1$ is sufficiently large, are in good agreement with the expectations, while the experimental data noticeably 


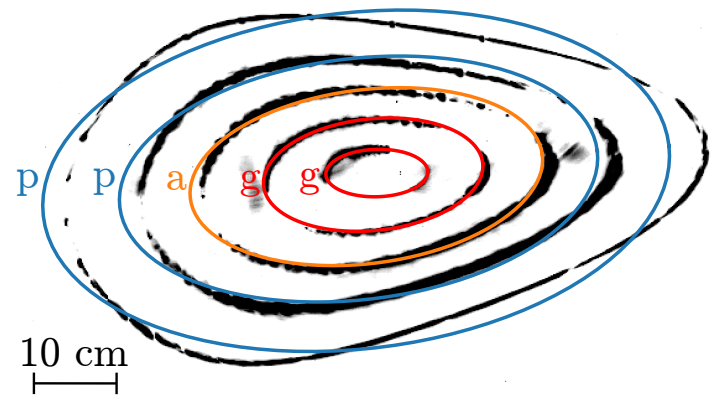

Figure 6: Example of ellipse fits to the flux surfaces. The experimental data correspond to figure $5 \mathrm{a}$ with the planar coil current $-10.2 \mathrm{kA}$. Three types of fits are illustrated: "g" - good quality fit; "a" - acceptable quality fit; "p" - poor quality fit.

deviate from the model for smaller radii, starting from the fifth flux surface counted from the outside. In the center, the shift is in the range of $10 \mathrm{~cm}$, directed mainly to the right. In contrast to this, no systematic shift of central flux surfaces is observed in the standard configuration, see figure 4 a. These results demonstrate unambiguously that a measurable $1 / 1$ field is indeed present in W7-X.

According to equation 2, the shift of flux surfaces due to $1 / 1$ field depends strongly on the rotational transform. The closer the rotational transform to the resonance, the longer field lines stay in phase with the perturbation, thus accumulating a larger displacement. The influence of the rotational transform was verified experimentally by varying the current in planar coils by about $\pm 0.8 \mathrm{kA}$ around the high-iota configuration. Figures $5 \mathrm{a}-5 \mathrm{~d}$ show central flux surfaces, where the $1 / 1$ effect is pronounced, for four configurations with the rotational transform on the axis reduced from about 1.02 to almost 1. As expected, the shift of flux surfaces increases as the rotational transform approaches 1, cases (a) to (c), while the topology with nested surfaces remains the same. If the rotational transform is very close to 1 , case (d), a structure resembling a 1/1 magnetic island appears. However, in this case it is not possible to conclude with certainty whether an island is formed, i.e. if a separate magnetic axis is present, as the measurements are obscured by a strong self-shadowing of the electron emitter. Simulations plotted in figure 5 $5 \mathrm{~d}$ include the $1 / 1$ perturbation as discussed below.

The 1/1 mode amplitude can be determined from the measurements above by using equation 2 with the following modification:

$$
|\delta x|=\frac{R_{0}\left|b_{11}\right|}{t-1} \cdot \frac{d x}{d r} .
$$

Here, $|\delta x|$ is the distance between the actual surface center and the ideal axis without the 1/1 error field effect. Measurements of the flux surface position are described below. The ideal axis position is assumed to coincide with the unperturbed field line tracing within about 5 pixels, as discussed above for the standard configuration in figure 4 a. The uncertainty of the ideal axis position contributes significantly to the uncertainty of the $1 / 1$ amplitude and of its phase. The derivative $d x / d r$ relative to effective radius is 


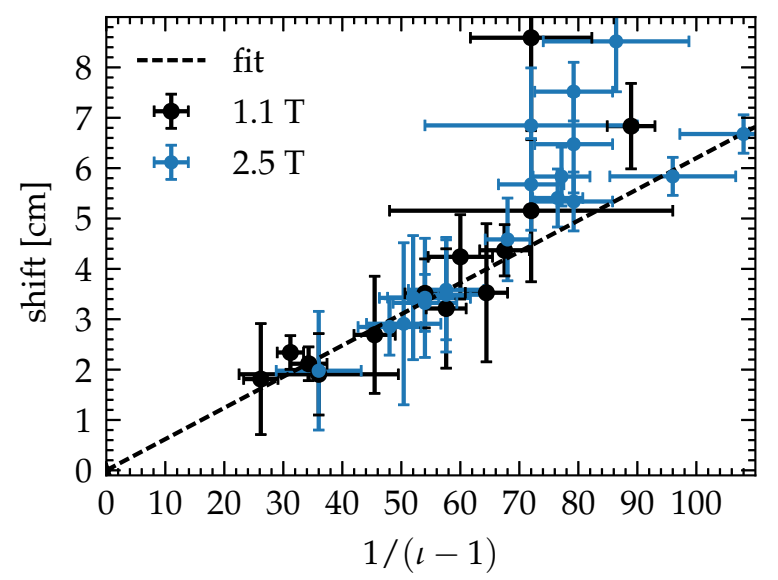

Figure 7: Dependence of the flux surface shift on the rotational transform. Measurements at two values of the magnetic field, 1.1 and $2.5 \mathrm{~T}$, are shown.

introduced to account for the shape of flux surfaces, i.e. for the ellipticity. The shift in physical space is different for different directions, but appears the same in terms of the effective radius. For the experimental situation in W7-X, where the shift is almost along the major axis of the ellipses, this derivative is estimated to be about 1.4 by using field line tracing. The values of rotational transform have to be also determined experimentally, because electromagnetic forces lead to a non-negligible reduction [22]. The $t$ estimation is performed for each flux surface by counting the number of toroidal transits required to cover a certain poloidal angle.

Displacement values $|\delta x|$ can be conveniently estimated by fitting ellipses to experimental data and taking distances from their centers to the ideal axis. This method is reliable for central flux surfaces of nearly elliptical shape and, therefore, only such flux surfaces are used for the further analysis. For example, only good ("g") and acceptable ("a") quality fits shown in figure [6] are included, whereas poor quality fits ("p") are omitted. It is worth noting that larger flux surfaces can also be used, if fitting with more Fourier harmonics is applied. A more elaborated fitting is not considered here, since the elliptical subset provides a sufficient number of data points. The displacement uncertainty is taken either as a typical deviation between the ellipse and the measured data or, for good quality fits, as a typical width of the fluorescent line.

The dependence of the flux surface shift $|\delta x|$ on the rotational transform is summarized in figure 7 for all flux surfaces of nearly elliptical shape shown previously in figures $4 \mathrm{~b}$, $5 \mathrm{5}-5 \mathrm{c}$. The shift scales linearly with the inverse difference $1 /(t-1)$ for shift values smaller than about $5 \mathrm{~cm}$. For larger displacements, the linear dependence is not evident, i.e. the linear assumption used to derive equation 2 is not sufficient. A similar behaviour was also observed in the numerical study in [30]. Using only the linear part of the data set in figure 7 one finds the $1 / 1$ amplitude of $(0.79 \pm 0.21) \cdot 10^{-4}$ by linear regression. The $1 / 1$ phase can be deduced from the direction of the flux surface shift. Shift directions calculated for phases of $0^{\circ}, 90^{\circ}, 180^{\circ}$ and $270^{\circ}$ are indicated in figure 5 c 
(a)

(b)
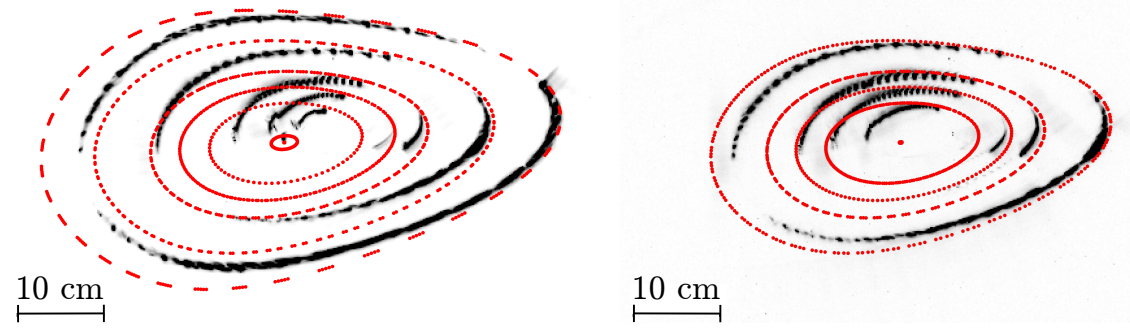

(c) $10 \mathrm{~cm}$

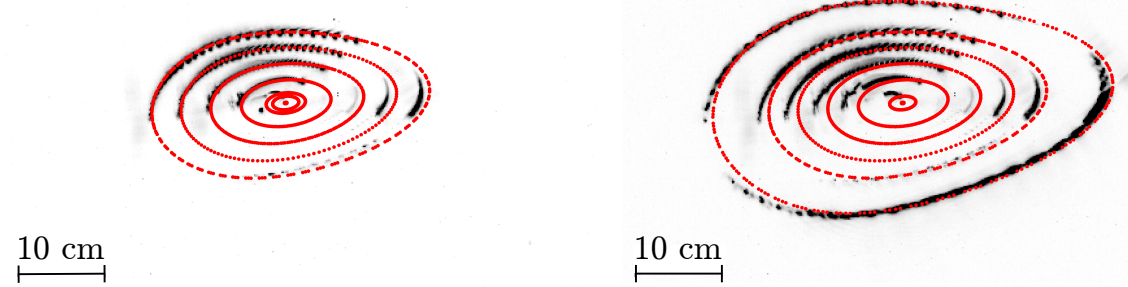

Figure 8: Compensation of the axis shift with trim coils. (a) - no trim coils applied; (b) - settings corresponding to $\left|b_{11}\right| \approx 0.42 \cdot 10^{-4}, 180^{\circ} ;(\mathrm{c})$ - settings corresponding to $\left|b_{11}\right| \approx 0.76 \cdot 10^{-4}, 180^{\circ} ;(\mathrm{d})$ - settings corresponding to $\left|b_{11}\right| \approx 0.85 \cdot 10^{-4}, 180^{\circ}$. Measurements are shown in black, simulation for the ideal case are shown in red.

for orientation. The experimental displacements are close to the reference $180^{\circ}$-case. Field line simulations taking into account the ideal axis uncertainty refine the $1 / 1$ phase to $170^{\circ} \pm 12^{\circ}$. Here, the phase is defined in the global W7-X coordinate system for the cosine of $\theta-\varphi$. According to this definition, the perturbation with phase of $0^{\circ}$ has its maximal outward pointing field at the outboard side in the plane $\varphi=0$.

To verify the validity of the result, field line simulations with superimposed $1 / 1$ field of $0.8 \cdot 10^{-4}$ and phase of $170^{\circ}$ are shown for the case of the extreme $1 / 1$ effect in figure $5 \mathrm{~d}$. A reasonable agreement with the experiment is indeed observed without any need for further adjustments, thus supporting the findings.

Measurements of the axis shift were performed for two values of the magnetic field, namely $1.1 \mathrm{~T}$ and $2.5 \mathrm{~T}$. No difference between the two cases is found, as can be seen in figure 7, which implies that the $1 / 1$ error field scales linearly with currents in the main coils. Hence, this error field is related either to errors in the coil geometries, coil positions, or to unsaturated ferromagnetic materials and not caused by deformations due to electromagnetic forces. In addition, the Earth's magnetic field, which was reported to be important for LHD at low fields [27], can be excluded as the 1/1 source.

\subsection{Compensation of the axis shift}

W7-X is fitted with two sets of normally conducting coils suitable for error field compensation: ten divertor control coils [4,6] and five trim coils [16]. Each of these coils can be energized independently. For the $1 / 1$ compensation, trim coils alone are 


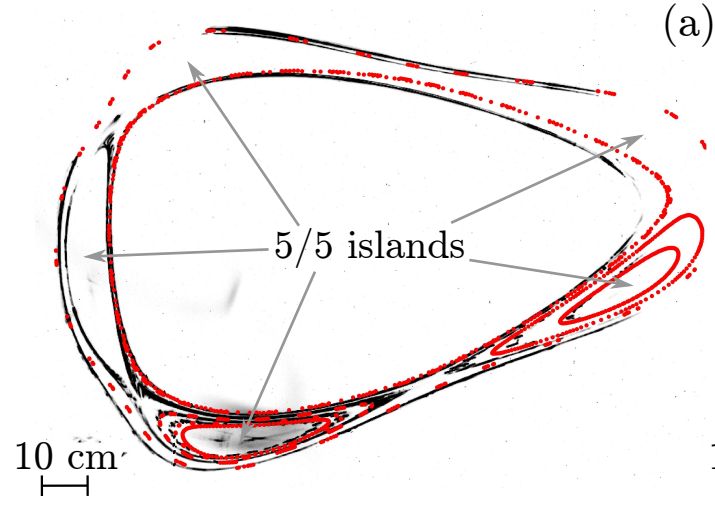

(a)

Figure 9: Measurements of the edge island structure in the narrow-mirror configuration with $-1.7 \mathrm{kA}$ in planar coils. (a) - a full set of measured surfaces. In red simulations with ideal coils are overlayed. (b) - 1/1 separatrix obtained for one fixed emitter position. White areas in the images are either caused by the self-shadowing, the limited motion range of the detector, or by the restricted camera view.

sufficient, which is demonstrated by the present flux surface measurements. If the phase and the amplitude of the target error field are defined, the counteracting currents in the trim coils can be readily determined from the linear superposition of Fourier spectra produced by individual coils.

The $1 / 1$ error field could be estimated to be about $0.8 \cdot 10^{-4}$ at the phase of roughly $180^{\circ}$ already during the measurement session. Given the target error field, the $1 / 1$ compensation with trim coils was tested. In these experiments, currents in the main coils were fixed with the planar coil current of $-9.8 \mathrm{kA}$ corresponding to the rotational transform on the axis of about 1.01, while currents in the trim coils were varied. Results of the compensation experiments are shown in figures $8 \mathrm{a}-\mathrm{d}$ alongside with ideal expected flux surfaces. A better agreement between the measurements and the model is obtained, if the trim currents are raised to the compensation target. The best compensation is achieved for trim currents corresponding to $\left|b_{11}\right| \approx 0.76 \cdot 10^{-4}$, whereas trim coil settings for $\left|b_{11}\right| \approx 0.85 \cdot 10^{-4}$ result in a slight overcompensation. This confirms the estimation of the $1 / 1$ error field and demonstrates the ability of trim coils to correct such perturbations.

Absolute values of the currents in the trim coils used for the compensation are below $150 \mathrm{~A}$. For comparison, the operational limit for the current in the trim coils is $1800 \mathrm{~A}$ for coils of type A (modules 1,3,4 and 5), and is $1950 \mathrm{~A}$ for coils of type B (module 2). Consequently, trim coils have sufficient capabilities also for compensation of higher order error fields.

\subsection{Measurements of the island structure}

Measurements of the axis shift in the high-iota configuration were complemented by measurements of the island structure at the resonance position of 1 , but in a different 
magnetic configuration. For this purpose, the narrow-mirror configuration with $5 / 5$ islands at the edge was used. This configuration is characterized by a large toroidal mirror to minimize the bootstrap current and a shifted strike line position as compared to the original high-mirror one. To avoid shadowing of islands by the divertor, the resonance was shifted inwards to $r / a$ of about 0.9 by raising the rotational transform with the help of about $-1.7 \mathrm{kA}$ in the planar coils. The application of planar coils restricted the operation to a field of $2.2 \mathrm{~T}$. Yet, the field restriction is not believed to be relevant, since the axis measurements show no dependence on it. Therefore, conditions for the flux surface mapping are very close to those during the plasma operation.

Results of the flux surface mapping around the resonant position in the narrow-mirror case are given in $9 \mathrm{a}$. Here, the $5 / 5$ divertor islands clearly dominate the edge. The internal structure of two of these islands was accessed in more details by placing the emitter inside them. Since all five islands are independent, such detailed measurements have to be performed for each island separately. This procedure was omitted for the remaining three islands to save time, because the island positions and their size are in reasonable agreement with the expectations. The position of the remaining three islands can be concluded from the separatrix shape. A deviation from the ideal geometry is observed in the right top corner, which is an indication of the presence of error fields. Remarkably, a clear signature of the $1 / 1$ error field is observed even without cancellation of the $5 / 5$ islands. The $1 / 1$ separatrix, i.e. with a single X-point, around the $5 / 5$ islands was obtained with a fixed emitter position, see figure 9b. The experimental difficulty is to strike the narrow separatrix region with a width on the order of $1 \mathrm{~cm}$. Such a separatrix is expected from the field line tracing with $1 / 1$ perturbation [16, 30, 31] and proves the $1 / 1$ presence. However, determining the $1 / 1$ amplitude from the full $1 / 1$ island width is erroneous, because a large fraction of the full width is due to the $5 / 5$ islands.

The 5/5 islands can be controlled with divertor control coils, which are ten coils, two per module, installed behind outboard baffles following the stellarator symmetry [4, 6]. If operated in the symmetrical mode, i.e. with inverted currents in two neighbouring half modules to match the stellarator flip symmetry of the field, they change the island size. If operated in the non-symmetric mode, i.e. with the same current direction in neighboring coils, they sweep the strike line position. In addition, since each coil can be energized independently, they are also suitable for the error field correction [14]. For the present experiments, the control coils were operated in the symmetric mode with the full current of $2.5 \mathrm{kA}$ to cancel out the $5 / 5$ islands.

Once the $5 / 5$ islands are nullified, the $1 / 1$ island can be identified, as shown in figure 10a. But even in this cases, the $1 / 1$ amplitude estimation is still not possible due to the simultaneous presence of the $2 / 2$ error field. When a partial $1 / 1$ compensation for the $1 / 1$ amplitude of about $0.4 \cdot 10^{-4}$ and the phase of $100^{\circ}$ is applied, the $2 / 2$ structure with two X-points in the poloidal cross-section becomes visible, see figure 10 b. The $2 / 2$ amplitude is estimated to be $(0.6 \pm 0.2) \cdot 10^{-4}$ by using equation 1 for the island width, and the $2 / 2$ phase of $-110^{\circ} \pm 40^{\circ}$ follows from the location of the X-points. The 
(a)
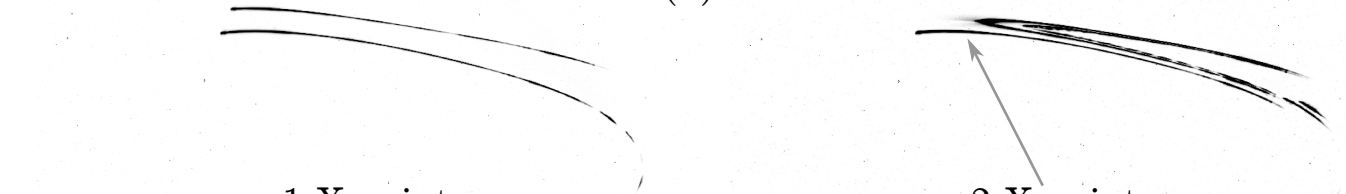

(b)
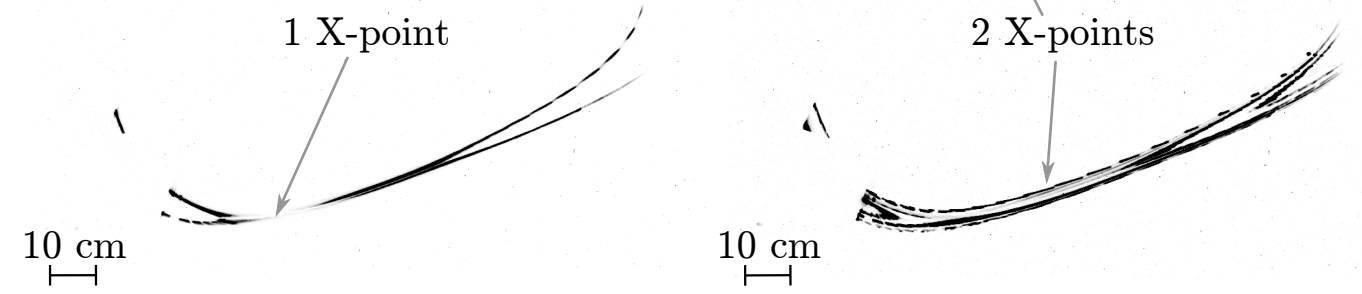

(c)
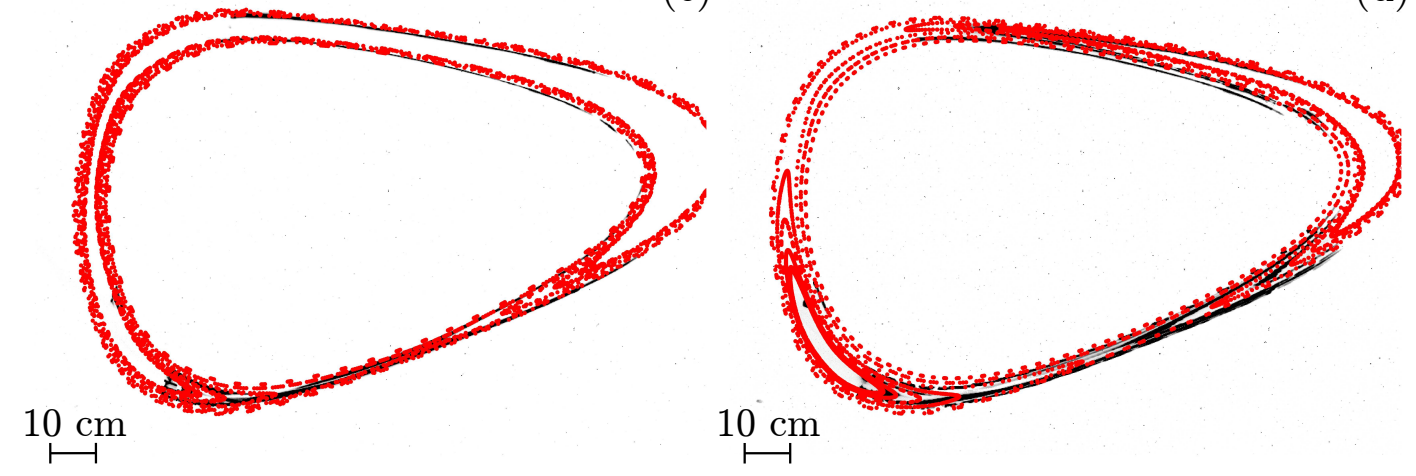

Figure 10: Error field measurements in the narrow-mirror configuration with cancelled $5 / 5$ islands. (a) $-1 / 1$ island. (b) $-2 / 2$ islands with $1 / 1$ compensation. (c) - the same as (a) but with field line tracing including $b_{11} \approx 0.5 \cdot 10^{-4}$ and $b_{22} \approx 0.6 \cdot 10^{-4}$; (d) - the same as (b) but with field line tracing including $b_{22} \approx 0.6 \cdot 10^{-4}$.

compensation of the $2 / 2$ perturbation was not attempted due to the lack of time. But this result is confirmed by a good agreement between the field line tracing including the found $2 / 2$ mode and the measurements, given in figure $10 \mathrm{~d}$. Given the $2 / 2$ estimation, it is possible to determine the $1 / 1$ error field by the trial-and-error field line tracing. Figure 10r demonstrates a good agreement between the measurements with the $5 / 5$ cancellation and the simulations with a combination of the $1 / 1$ and $2 / 2$ perturbations. The $1 / 1$ amplitude is evaluated to be $(0.5 \pm 0.2) \cdot 10^{-4}$ and the $1 / 1$ phase is about $140^{\circ}$ without a clearly defined uncertainty. It is interesting to note that, if one were to interpret the full island width in figure 10a as the $1 / 1$ width, one would overestimate the $1 / 1$ amplitude to be about $0.7 \cdot 10^{-4}$.

\subsection{Symmetry of divertor loads}

The $1 / 1$ error field found with flux surfaces mapping is in the range where a measurable effect on the power distribution between divertors is expected, as follows from the dependence in figure 1. The asymmetry, i.e. a violation of the equal power partitioning, is indeed observed during plasma operation in $5 / 5$ configurations. It is measured, for 


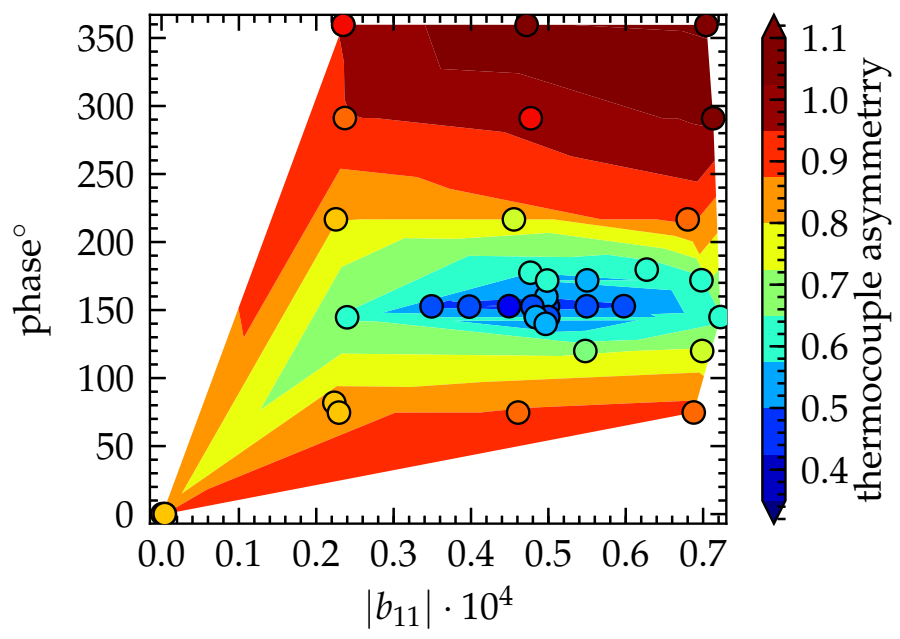

Figure 11: Divertor power asymmetry measured with thermocouples for different trim coil settings in the narrow-mirror configuration. The trim coil settings are given as the phase and the amplitude of the 1/1 field they compensate. The measured points are plotted with circles. The coloured background is an interpolated contour plot. The asymmetry is defined here as relative amplitude of the temperature variation between divertor modules measured in identical positions and averaged over all of them.

example, with in total one hundred thermocouples installed at the backside of all ten divertors, i.e. ten thermocouples per divertor. The thermocouples are placed in the same positions in each divertor unit: four locations in the low-iota part of horizontal targets, three locations in the high-iota part of horizontal targets, and three locations in vertical targets. It is possible to conclude about the symmetry of divertor loads by comparing signals from thermocouples in identical locations in different divertors. Because of the thermal inertia of the carbon tiles in front of them, thermocouple signals still increase after the plasma termination for about 10-20 s. These temperature increments are assumed proportional to the energy deposited to the tiles in front. By averaging data from available thermocouples, it is found that divertor power fractions are not the same between the modules, i.e. an asymmetry is present.

The symmetry of the power distribution is improved, if suitable trim coil settings are applied. The trim coil settings can be determined experimentally from the phase and amplitude scan of the 1/1 field generated by them. During such a scan, a series of identical plasma discharges was performed and only the trim coil currents were changed to identify the most symmetric case. Typical plasma parameters are: ECRH heating power of about $2 \mathrm{MW}$, line averaged electron density of about $1 \cdot 10^{19} \mathrm{~m}^{-3}$, plasma duration of about $2 \mathrm{~s}$. Results of the compensation scan for the narrow-mirror configuration are presented in figure11 in the phase-amplitude plane of the compensated $1 / 1$ error field. The colour of experimental points shows relative amplitude of the temperature variation between divertor modules measured by the thermocouples in 
identical positions and averaged over all these positions:

$$
\frac{1}{M} \sum_{m} \frac{\max _{n} T_{m n}-\min _{n} T_{m n}}{2\left\langle T_{m n}\right\rangle_{n}},
$$

where $m$ is the thermocouple position in one divertor unit, $n$ is the toroidal module, $M$ is the total number of thermocouple locations, $T_{m n}$ is the temperature in the $m$-th thermocouple in module $n$ and $\left\langle T_{m n}\right\rangle_{n}$ is the toroidal average of thermocouple signals in position $m$. This value should be zero in the ideal case. A global minimum in the asymmetry is identified for the trim coil settings compensating the $1 / 1$ error field of about $0.45 \cdot 10^{-4}$ at the phase of about $150^{\circ}$. This is in good agreement with the $1 / 1$ error field determined with flux surface mapping; and, consequently, a large part of the asymmetry is due to this error field. The achieved reduction of the asymmetry amplitude is about a factor of two compared to the case without compensation, i.e. zero amplitude in the figure.

It is to be noted that the improvement in the symmetry is observed on average between thermocouples in different locations and that for some locations the improvement is not clear. This, or equivalently the remaining asymmetry, can be explained by several possible causes: slight misplacements of the thermocouples, misalignments of divertor targets, and presence of the $2 / 2$ error field. The improved symmetry of the power distribution with the $1 / 1$ compensation is also found from measurements with infrared cameras available in all ten divertor units. But the latter results will be reported separately once the analysis is finalized [32,33].

\section{Summary}

The flux surface measurements clearly show presence of the $1 / 1$ error field in Wendelstein 7-X. This is confirmed with two methods: (i) measurements of the axis shift in the highiota configuration; and (ii) measurements of the island structure in the narrow-mirror configuration with $5 / 5$ islands cancelled by the control coils. The found normalized $1 / 1$ amplitudes for the two configurations are about $0.8 \cdot 10^{-4}$ and about $0.5 \cdot 10^{-4}$ respectively, though with significant error bars. The difference between the two configurations can be preliminary explained by the much higher planar coil current in the high-iota configuration. It follows that the planar coils result in a higher $1 / 1$ perturbation, which is not surprising, because the module positioning was optimized to counteract error fields due to non-planar coils only.

The 1/1 error field does not depend on the amplitude of the magnetic field, as demonstrated by measurements of the axis shift in the high-iota configuration at the field of 1.1 and $2.5 \mathrm{~T}$. Therefore, the 1/1 error field is due to either manufacturing errors of the coil, their misalignments or due to unsaturated ferromagnetic materials, and not caused by electromagnetic deformations. The amplitude of the $1 / 1$ perturbation is in the range expected due to the assembly steps that followed the final module adjustment [15]. However, a suitable model of the coils still has to be developed.

The $1 / 1$ error field can be compensated with five trim coils available for this purpose. 
The compensation was demonstrated with both approaches for the flux surface mapping and requires only about $5 \%$ of the current allowed in the trim coils. This leaves enough capability for the compensation of higher error fields. The $1 / 1$ compensation helps also to identify the $2 / 2$ error field of about $0.6 \cdot 10^{-4}$ in the measurements of the edge island structure. Thus, the edge island structure in $5 / 5$ divertor configurations is a combination of the $5 / 5$ field of about $3 \cdot 10^{-4}, 1 / 1$ field of about $0.5 \cdot 10^{-4}$ and of the $2 / 2$ field of about $0.6 \cdot 10^{-4}$. The $2 / 2$ compensation was not achieved yet mainly due to the experimental time limitations, but both control coils and trim coils are available for this.

The presence of the $1 / 1$ error field is also confirmed by the asymmetry in the power partitioning between divertors during plasma operation in $5 / 5$ configurations. The asymmetry is detected by using thermocouples installed at the back side of the targets and with infrared observations. It is possible to improve the symmetry by compensating the $1 / 1$ error field with trim coils. The most symmetric case in the narrow-mirror configuration is found for the compensation of the $1 / 1$ mode of about $0.45 \cdot 10^{-4}$, which is close to the result of flux surfaces mapping. Hence, it is confirmed that the $1 / 1$ error field has a significant effect on the divertor loads and that a large part of the observed divertor asymmetry is due to the intrinsic $1 / 1$ field. The asymmetry remaining after the $1 / 1$ correction can be caused by the $2 / 2$ error field and misalignments of targets.

Future error field studies at W7-X will be able to address changes of found error fields between experimental campaigns, clarify subtle configuration differences, and test compensation of the $2 / 2$ error field. This will help to clarify the source of error fields and to create a validated coil model. But already now it is obvious that the high construction accuracy of W7-X helped to minimize error fields to the level below $10^{-4}$ and that these residual perturbations are well within capabilities of the control and trim coils available for their correction. The error field compensation, shown here for the $1 / 1$ mode, is one of ingredients for achieving high performance steady state operation of W7-X.

\section{Acknowledgments}

The authors would like to thank Dr. T. Andreeva, Dr. M. Endler and Dr. J. Kißlinger for useful discussions, Dr. V. Bykov for the technical support and Ms. R. Wolf for the programming assistance.

This work has been carried out within the framework of the EUROfusion Consortium and has received funding from the Euratom research and training programme 20142018 under grant agreement No 633053. The views and opinions expressed herein do not necessarily reflect those of the European Commission.

\section{References}

[1] Grieger G, Beidler C, Harmeyer E, Junker J, Kißlinger J, Lotz W, Merkel P, Montvai A, Nührenberg J, Rau F, Schlüter A, Wobig H and Zille R 1989 Physics studies for helical-axis advanced stellarators Plasma Physics and Controlled Nuclear Fusion Research, Proceedings of the 12th International Conference, Nice, 1988 vol 2 (IAEA, Vienna) pp $369-387$ 
[2] Beidler C, Grieger G, Herrnegger F, Harmeyer E, Kißlinger J, Lotz W, Maaßberg H, Merkel P, Nührenberg J, Rau F, Sapper J, Sardei F, Scardovelli R, Schlüter A and Wobig H 1990 Fusion Technology 17 148-168

[3] Wolf R C, Beidler C D, Dinklage A, Helander P, Laqua H P, Schauer F, Pedersen T S and Warmer F 2016 IEEE Transactions on Plasma Science 44 1466-1471 ISSN 0093-3813

[4] Renner H, Boscary J, Erckmann V, Greuner H, Grote H, Sapper J, Speth E, Wesner F and Wanner M 2000 Nuclear Fusion 401083 - 1093

[5] Kißlinger J, Beidler C D, Harmeyer E, Rau F, Renner H and Wobig H 1994 Island divertor for the stellarator Wendelstein 7-X Controlled Fusion and Plasma Physisc, Proceedings of 21st European Conference, Montpellier, 1994 vol 18B, part 1 (European Physical Society, Geneva) pp $368-371$

[6] Greuner H, Bitter W, Kerl F, Kißlinger J and Renner H 1995 Structure of divertor for the optimized stellarator W7-X Fusion Technology, Proceedings of 18th Symposium Karlsruhe, 1994 vol 1 (Elsevier, Amsterdam and New-York) pp $323-326$

[7] König R, Grigull P, McCormick K, Feng Y, Kisslinger J, Komori A, Masuzaki S, Matsuoka K, Obiki T, Ohyabu N, Renner H, Sardei F, Wagner F and Werner A 2002 Plasma Physics and Controlled Fusion 442365 URL http://stacks.iop.org/0741-3335/44/i=11/a=306

[8] Feng Y, Beidler C, Geiger J, Helander P, Hölbe H, Maassberg H, Turkin Y, Reiter D and W7-X Team 2016 Nuclear Fusion 56126011 URL http://stacks.iop.org/0029-5515/56/i=12/a=126011

[9] Feng Y, Kobayashi M, Lunt T and Reiter D 2011 Plasma Physics and Controlled Fusion 53024009 URL http://stacks . iop. org/0741-3335/53/i=2/a=024009

[10] Andreeva T, Kisslinger J and Wobig H 2002 Characteristics of main configurations of Wendelstein 7-X Problems of Atomic Science and Technology Series: Plasma Physics vol 4 (Kharkov: National Science Center, Kharkov Institute of Physics and Technology) pp 45-47 URL http://vant.kipt.kharkov.ua/ARTICLE/VANT_2002_4/article_2002_4_45.pdf

[11] Geiger J, Beidler C D, Feng Y, Maaßberg H, Marushchenko N B and Turkin Y 2015 Plasma Physics and Controlled Fusion 57014004 URL http://stacks . iop.org/0741-3335/57/i=1/a=014004

[12] Bozhenkov S, Geiger J, Grahl M, Kißlinger J, Werner A and Wolf R C 2013 Fusion Engineering and Design 8829973006

[13] Braeuer T, Havemeister R, Henkel A and Mueller J 2014 IEEE Transactions on Plasma Science 42 1943-1950 ISSN 0093-3813

[14] Kißlinger $\mathrm{J}$ and Andreeva $\mathrm{T} 2005$ Fusion Engineering and Design 74623 - 626 ISSN 0920-3796 Proceedings of the 23rd Symposium of Fusion Technology (SOFT 23) URL http://www.sciencedirect.com/science/article/pii/S0920379605002590

[15] Andreeva T, Bräuer T, Bykov V, Egorov K, Endler M, Fellinger J, Kißlinger J, Köppen M and Schauer F 2015 Nuclear Fusion 55063025 URL http://stacks.iop.org/0029-5515/55/i=6/a=063025

[16] Rummel T, Riße K, Kißlinger J, Koppen M, Fullenbach F, Neilson H, Brown T and Ramakrishnan S 2012 Applied Superconductivity, IEEE Transactions on 224201704 ISSN 1051-8223

[17] Pedersen T S, Andreeva T, Bosch H S, Bozhenkov S, Effenberg F, Endler M, Feng Y, Gates D, Geiger J, Hartmann D, Hölbe H, Jakubowski M, König R, Laqua H, Lazerson S, Otte M, Preynas M, Schmitz O, Stange T, Turkin Y and the W7-X Team 2015 Nuclear Fusion 55126001 URL http://stacks.iop.org/0029-5515/55/i=12/a=126001

[18] Klinger T, Alonso A, Bozhenkov S, Burhenn R, Dinklage A, Fuchert G, Geiger J, Grulke O, Langenberg A, Hirsch M, Kocsis G, Knauer J, Krämer-Flecken A, Laqua H, Lazerson S, Landreman M, Maaßberg H, Marsen S, Otte M, Pablant N, Pasch E, Rahbarnia K, Stange T, Szepesi T, Thomsen H, Traverso P, Velasco J L, Wauters T, Weir G, Windisch T and The Wendelstein 7-X Team 2017 Plasma Physics and Controlled Fusion 59014018 URL http://stacks .iop.org/0741-3335/59/i=1/a=014018

[19] Wolf R, Ali A, Alonso A, Baldzuhn J, Beidler C, Beurskens M, Biedermann C, Bosch H S, 
Bozhenkov S, Brakel R, Dinklage A, Feng Y, Fuchert G, Geiger J, Grulke O, Helander P, Hirsch M, Höfel U, Jakubowski M, Knauer J, Kocsis G, König R, Kornejew P, Krämer-Flecken A, Krychowiak M, Landreman M, Langenberg A, Laqua H, Lazerson S, Maßberg H, Marsen S, Marushchenko M, Moseev D, Niemann H, Pablant N, Pasch E, Rahbarnia K, Schlisio G, Stange T, Pedersen T S, Svensson J, Szepesi T, Mora H T, Turkin Y, Wauters T, Weir G, Wenzel U, Windisch T, Wurden G, Zhang D, Abramovic I, Äkäslompolo S, Aleynikov P, Aleynikova K, Alzbutas R, Anda G, Andreeva T, Ascasibar E, Assmann J, Baek S G, Banduch M, Barbui T, Barlak M, Baumann K, Behr W, Benndorf A, Bertuch O, Biel W, Birus D, Blackwell B, Blanco E, Blatzheim M, Bluhm T, Böckenhoff D, Bolgert P, Borchardt M, Borsuk V, Boscary J, Böttger L G, Brand H, Brandt C, Bräuer T, Braune H, Brezinsek S, Brunner K J, Brünner B, Burhenn R, Buttenschön B, Bykov V, Calvo I, Cannas B, Cappa A, Carls A, Carraro L, Carvalho B, Castejon F, Charl A, Chernyshev F, Cianciosa M, Citarella R, Ciupiski , Claps G, Cole M, Cole M, Cordella F, Cseh G, Czarnecka A, Czermak A, Czerski K, Czerwinski M, Czymek G, da Molin A, da Silva A, Dammertz G, Danielson J, de la Pena A, Degenkolbe S, Denner P, Dhard D, Dostal M, Drevlak M, Drewelow P, Drews P, Dudek A, Dundulis G, Durodie F, van Eeten P, Effenberg F, Ehrke G, Endler M, Ennis D, Erckmann E, Esteban H, Estrada T, Fahrenkamp N, Feist J H, Fellinger J, Fernandes H, Fietz W, Figacz W, Fontdecaba J, Ford O, Fornal T, Frerichs H, Freund A, Führer M, Funaba T, Galkowski A, Gantenbein G, Gao Y, Regana J G, Garcia-Munoz M, Gates D, Gawlik G, Geiger B, Giannella V, Gierse N, Gogoleva A, Goncalves B, Goriaev A, Gradic D, Grahl M, Green J, Grosman A, Grote H, Gruca M, Guerard C, Haiduk L, Han X, Harberts F, Harris J, Hartfu H J, Hartmann D, Hathiramani D, Hein B, Heinemann B, Heitzenroeder P, Henneberg S, Hennig C, Sanchez J H, Hidalgo C, Hölbe H, Hollfeld K, Hölting A, Höschen D, Houry M, Howard J, Huang X, Huber M, Huber V, Hunger H, Ida K, Ilkei T, Illy S, Israeli B, Ivanov A, Jablonski S, Jagielski J, Jelonnek J, Jenzsch H, Junghans P, Kacmarczyk J, Kaliatka T, Kallmeyer J P, Kamionka U, Karalevicius R, Kasahara H, Kasparek W, Kenmochi N, Keunecke M, Khilchenko A, Kinna D, Kleiber R, Klinger T, Knaup M, Kobarg T, Köchl F, Kolesnichenko Y, Könies A, Köppenppen M, Koshurinov J, Koslowski R, Köster F, Koziol R, Krämer M, Krampitz R, Kraszewsk P, Krawczyk N, Kremeyer T, Krings T, Krom J, Krzesinski G, Ksiazek I, Kubkowska M, Kühnerhner G, Kurki-Suonio T, Kwak S, Lang R, Langish S, Laqua H, Laube R, Lechte C, Lennartz M, Leonhardt W, Lewerentz L, Liang Y, Linsmeier C, Liu S, Lobsien J F, Loesser D, Cisquella J L, Lore J, Lorenz A, Losert M, Lubyako L, Lcke A, Lumsdaine A, Lutsenko V, Majano-Brown J, Marchuk O, Mardenfeld M, Marek P, Massidda S, Masuzaki S, Maurer D, McCarthy K, McNeely P, Meier A, Mellein D, Mendelevitch B, Mertens P, Mikkelsen D, Mishchenko O, Missal B, Mittelstaedt J, Mizuuchi T, Mollen A, Moncada V, Mönnich T, Morizaki T, Munk R, Murakami S, Musielok F, Nafradi G, Nagel M, Naujoks D, Neilson H, Neubauer O, Neuner U, Ngo T, Nocentini R, Nührenberg C, Nührenberg J, Obermayer S, Offermanns G, Ogawa K, Ongena J, Oosterbeek J, Orozco G, Otte M, Rodriguez L P, Pan W, Panadero N, Alvarez N P, Panin A, Papenfuß D, Paqay S, Pavone A, Pawelec E, Pelka G, Peng X, Perseo V, Peterson B, Pieper A, Pilopp D, Pingel S, Pisano F, Plaum B, Plunk G, Povilaitis M, Preinhaelter J, Proll J, Puiatti M E, Sitjes A P, Purps F, Rack M, Recsei S, Reiman A, Reiter D, Remppel F, Renard S, Riedl R, Riemann J, Rimkevicius S, Riße K, Rodatos A, Röhlinger H, Rom M, Rong P, Roscher H J, Roth B, Rudischhauser L, Rummel K, Rummel T, Runov A, Rust N, Ryc L, Ryosuke S, Sakamoto R, Samartsev A, Sanchez M, Sano F, Satake S, Satheeswaran G, Schacht J, Schauer F, Scherer T, Schlaich A, Schlüter K H, Schmitt J, Schmitz H, Schmitz O, Schmuck S, Schneider M, Schneider W, Scholz M, Scholz P, Schrittwieser R, Schröder M, Schröder T, Schroeder R, Schumacher H, Schweer B, Shanahan B, Shikhovtsev I, Sibilia M, Sinha P, Sipli S, Skodzik J, Slaby C, Smith H, Spiess W, Spong D, Spring A, Stadler R, Standley B, Stephey L, Stoneking M, Stridde U, Sulek Z, Surko C, Suzuki Y, Szabo V, Szabolics T, Szökefalvi-Nagy Z, Tamura N, Terra A, Terry J, Thomas J, Thomsen H, Thumm M, von Thun C, Timmermann D, Titus P, Toi K, Travere J, Traverso P, Tretter J, Tsuchiya H, Tsujimura T, Tulipan S, Turnyanskiy M, Unterberg B, Urban J, Urbonavicius E, 
Vakulchyk I, Valet S, van Millingen B, Vela L, Velasco J L, Vergote M, Vervier M, Vianello N, Viebke H, Vilbrandt R, Vorkörper A, Wadle S, Wagner F, Wang E, Wang N, Warmer F, Wegener L, Weggen J, Wei Y, Wendorf J, Werner A, Wiegel B, Wilde F, Winkler E, Winters V, Wolf S, Wolowski J, Wright A, Xanthopoulos P, Yamada H, Yamada I, Yasuhara R, Yokoyama M, Zajac J, Zarnstorff M, Zeitler A, Zhang H, Zhu J, Zilker M, Zimbal A, Zocco A, Zoletnik S and Zuin M 2017 Nuclear Fusion 57102020 URL http://stacks .iop.org/0029-5515/57/i=10/a=102020

[20] Bozhenkov S, Effenberg F, Feng Y, Geiger J, Hartmann D, Hölbe H, Pederson T and Wolf R 2014 Limiter for the early operation phase of W7-X 41st EPS Conf. on Plasma Physics, Berlin, Germany (2014), P-1.080 URL http://ocs.ciemat.es/EPS2014PAP/pdf/P1.080.pdf

[21] Pedersen T S, Otte M, Lazerson S, Helander P, Bozhenkov S, Biedermann C, Klinger T, Wolf R C, Bosch H S and Team T W X 2016 Nature Communications 713493 EP - article URL http://dx.doi.org/10.1038/ncomms13493

[22] Otte M, Aßmus D, Biedermann C, Bozhenkov S, Bräuer T, Dudek A, Geiger J, Kocsis G, Lazerson S, Pedersen T S, Schauer F, Szepesi T, Standley B and the W7-X Team 2016 Plasma Physics and Controlled Fusion 58064003 URL http://stacks.iop.org/0741-3335/58/i=6/a=064003

[23] Lazerson S A, Otte M, Bozhenkov S, Biedermann C, Pedersen T S and the W7-X Team 2016 Nuclear Fusion 56106005 URL http://stacks .iop.org/0029-5515/56/i=10/a=106005

[24] Bozhenkov S, Jakubowski M, Niemann H, Lazerson S, Wurden G, Biedermann C, Kocsis G, König R, Pisano F, Stephey L, Szepesi T, Wenzel U, Pedersen T, Wolf R and W7-X Team 2017 Nuclear Fusion 57126030 URL http://stacks .iop.org/0029-5515/57/i=12/a=126030

[25] Lazerson S A, Otte M, Jakubowski M, Israeli B, Wurden G A, Wenzel U, Andreeva T, Bozhenkov S, Biedermann C, Kocsis G, Szepesi T, Geiger J, Pedersen T S, Gates D and the W7-X Team 2017 Nuclear Fusion 57046026 URL http://stacks .iop.org/0029-5515/57/i=4/a=046026

[26] Sunn Pedersen T, Dinklage A, Turkin Y, Wolf R, Bozhenkov S, Geiger J, Fuchert G, Bosch H S, Rahbarnia K, Thomsen H, Neuner U, Klinger T, Langenberg A, Trimio Mora H, Kornejew P, Knauer J, Hirsch M and Pablant N 2017 Physics of Plasmas 24055503 (Preprint https://doi.org/10.1063/1.4983629) URL https://doi.org/10.1063/1.4983629

[27] Morisaki T, Shoji M, Masuzaki S, Sakakibara S, Yamada H, Komori A and Motojima O 2010 Fusion Science and Technology $\mathbf{5 8} 465-470$

[28] Jaenicke R, Ascasibar E, Grigull P, Lakicevic I, Weller A, Zippe M, Hailer H and Schworer K 1993 Nuclear Fusion 33687 URL http://stacks.iop.org/0029-5515/33/i=5/a=I02

[29] Boozer A $\mathrm{H} \quad 2005$ Rev. Mod. Phys. 76(4) 1071-1141 URL http://link.aps.org/doi/10.1103/RevModPhys.76.1071

[30] Bozhenkov S, Lazerson S, Otte M, Gates D, Pedersen T S and Wolf R 2016 Nuclear Fusion 56 076002 URL http://stacks . iop.org/0029-5515/56/i=7/a=076002

[31] Kißlinger J and Andreeva T 2006 Fusion Science and Technology 50 382-386

[32] Lazerson S 2018 to be submitted to PPCF

[33] Drewelow P 2018 to be submitted 